\title{
ISOLATION AND CHARACTERIZATION OF STEROLS AND AN ALIPHATIC ALCOHOL FROM TSUGA DUMOSA D. DON OF NEPAL
}

\author{
Ramesh C. Dhakal*, Surya K. Kalauni*, Suresh Awale**, Kanti Shrestha***, Mohan B. Gewali* \\ *Central Department of Chemistry, Tribhuvan University, Kirtipur, Kathmandu, Nepal. \\ **Division of Natural Product Chemistry, Institute of Natural Medicine, University of Toyama, 2630 Sugitani, \\ Toyama 930-0194, J apan. \\ ***Nepal Academy of Science and Technology (NAST), Khumaltar, Lalitpur, Nepal.
}

\begin{abstract}
In the course of our continuing research on Himalayan conifers, the phytochemical screening and isolation of chemical constituents of Tsuga dumosa D. Don of Nepali origin was carried out. Three sterols, namely $\hat{a}$-sitosterol (1), stigmasterol (2), $\hat{a}$-sitosterol glucoside (3) and an alcohol, nonacosan-10-ol (4) were isolated. Their structures were elucidated on the basis of spectroscopic evidences.
\end{abstract}

Key Words: Phytochemical screening; Tsuga dumosa; Sterols; Nonacosan-10-ol.

\section{INTRODUCTION}

Tsuga dumosa D. Don is an economically as well as medicinally important conifer belonging to family Pinaceae. ${ }^{1,2}$ It is commonly known as "Hemlock Spruce" and locally called as "Dhupi" or "Thingre Salla”. In Nepal, it is found in the northern belt mainly in the damp and adverse areas of Sagarmatha National Park at an altitude of 2100-3600 $\mathrm{m}$ in association with other conifers like Taxus, Abies and Picea. ${ }^{3}$ The plant has been extensively used for timbering and lumber products because of its resistance to decay. The bark of this plant is a rich source of tannin, hence can be used for dying. ${ }^{4}$ A solid self bioadhesive herbal compound isolated from T. dumosa was used for the tropical treatment of the oral mucosal disorder and for patients exhibiting herpetic stomatities lesions, aphthous ulcers, mucosal inflammation, toothache and lesions on the lips and gingival. ${ }^{5}$ Among the isolated compounds from $T$. dumosa include lignans, sesquilignan, dumosaol, along with some other lignans. ${ }^{6,7}$ In the course of our continuing research on Himalayan conifers, ${ }^{8}$ the present study has resulted on isolation of $\hat{a}$-sitosterol, stigmasterol, $\hat{a}$-sitosterol glucoside and nonacosan-10-ol from Tsuga dumosa D. Don (Fig. 1). The structures of the isolated compounds were assigned mainly on the basis of their spectral data.

\section{MATERIALS AND METHODS}

General Experimental Procedure: Melting point was measured on electronic melting point apparatus (Ogawa Seiki Co. LTD, Tokyo, Japan) and was uncorrected. IR spectra were obtained on neat using Perkin Emler 1310 Infrared Spectrophotometer. Mass spectra were carried out on JEOL MSRoute. ${ }^{1} \mathrm{H}$-NMR and ${ }^{13} \mathrm{C}-\mathrm{NMR}$ spectra were obtained on
Brukner WM400 NMR spectrometer. Thin layer chromatography (TLC) was carried out on silica gel G precoated plates. Separation and purification were performed by column chromatography on silica gel (60-120 mesh)

Plant Material: The fresh twigs of T. dumosa were collected from the Nammo-Bauddha area of Kavrepalanchock district during August, 2004 and were identified by Prof. Dr. R. P. Chaudhary, Professor of Central Department of Botany, Tribhuvan University, Kirtipur, Kathmandu, Nepal. Voucher specimen was deposited at National Herbarium and Plant Laboratories, Godawari, Lalitpur, Nepal.

Extraction and Isolation: The air dried twigs of T. dumosa $(1.0 \mathrm{Kg})$ were extracted with $5 \mathrm{~L}$ ethyl alcohol $(\mathrm{EtOH})(90 \% \times$ 3) at around $60^{\circ} \mathrm{C}$ for 6 hrs. The crude $\mathrm{EtOH}$ extract was evaporated in vacuum. The residue was subjected to fractionation by using hexane, chloroform, n-butyl alcohol to get respective fractions. Hexane and chloroform fractions were subjected to column chromatography on silica gel, eluted with different polarity. From hexane fraction compound 1 (7.0 $\mathrm{mg}$ ), 2 (12.0 mg), and 4 (38.0 mg) were isolated and compound 3 (16.0 mg) was isolated from chloroform fraction (Fig. 1).

\section{RESULTS AND DISCUSSION}

Phytochemical screening of T. dumosa showed the presence of volatile oil, fatty acids, triterpenes, sterols, carotenoids, polyphenols, reducing compounds, anthracenocoids, coumarins, flavone aglycones, tannins and saponins. In the light of the phytochemical sceening, we decided to examine hexane and chloroform fractions for finding boactive compounds and therefore these fractions were subjected to column chromatography on silica gel, eluted with solvent of

Author for Correspondence: Prof. Dr. Mohan B. Gewali, Central Department of Chemistry, Tribhuvan University, Kirtipur, Kathmandu, Nepal. Email: gewalimb@gmail.com. 
increasing polarity. From hexane fraction compound 1 (7.0 $\mathrm{mg}$ ), 2 (12.0 mg), and $\mathbf{4}$ (38.0 mg) were isolated and compound 3 (16.0 mg) was isolated from chloroform fraction (Fig. 1).

Compound 1 was a crystalline, melted at $135^{\circ} \mathrm{C}$. It gave positive Libermann-Burchard test with greenish red color indicating the compound to be sterol. The mass spectrum showed $\mathrm{M}^{+}$at $\mathrm{m} / \mathrm{z}$ at 414 corresponding to the molecular formula $\mathrm{C}_{29} \mathrm{H}_{50} \mathrm{O}$. The IR spectrum showed presence of - $\mathrm{OH}$ group at $3400 \mathrm{~cm}^{-1}$ and a peak at $1063 \mathrm{~cm}^{-1}$ corresponding to $-\mathrm{C}-\mathrm{O}$ group. Two singlets at ä 1.02 and at 0.66 are methyl group of C-19 and C-18 respectively. The doublets at ä $0.93(\mathrm{~d}, J=6.1 \mathrm{~Hz}) ; 0.81(\mathrm{~d}, J=$ $6.9 \mathrm{~Hz}) ; 0.82(\mathrm{~d}, J=6.9 \mathrm{~Hz})$ and $0.84(\mathrm{t}, J=7.3 \mathrm{~Hz})$ were accounted for methyl group at C-21, C-25, C-27 and C-29. A signal at ä 5.33 in ${ }^{1} \mathrm{H}-\mathrm{NMR}$ can be accounted for an olefinic proton $\mathrm{H}-6$ and a multiplet at ä 3.50 equivalent to a proton was assigned for the proton $\mathrm{H}-3$. The low field signal of $\mathrm{H}-3$ due to the attachment of $\hat{a}-\mathrm{OH}$ group at C-3 carbon. Thus, the assignment of hydroxyl group at C-3 and the double bond at C-5 were assigned accordingly. Three multiplets equivalent to two protons each appeared at ä 1.82, 1.97 and 2.26 were assigned for three $\mathrm{CH}_{2}$ groups. The remaining protons have appeared as multiplets at ä 1.05-1.54. From IR spectroscopy, mass and NMR spectroscopic data and comparison with reported spectral data and comparison of TLC with authentic sample, the compound was assigned as â-sitosterol.

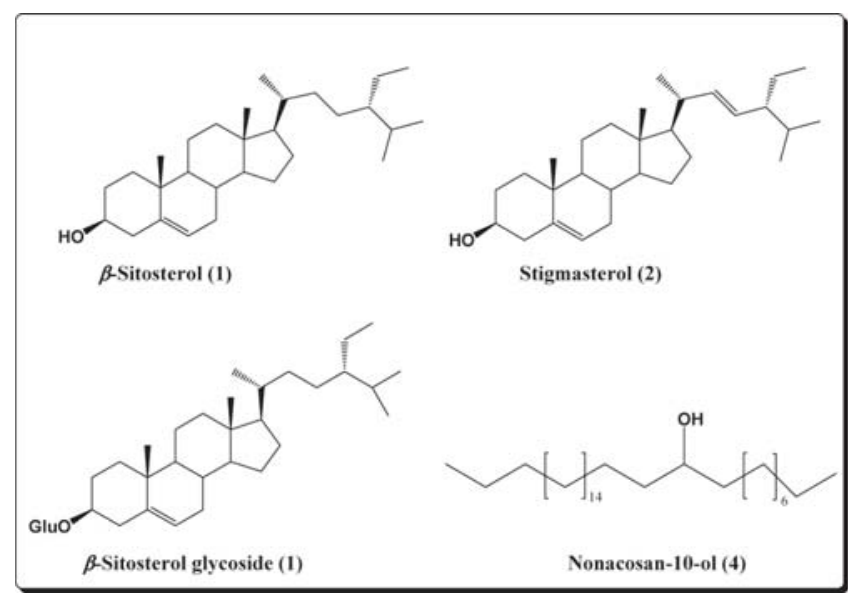

Fig.1: Structure of isolated compound

The compound 2 was white crystalline having melting point $165^{\circ} \mathrm{C}$. It gave positive Libermann-Burchard test with greenish red color indicating the compound to be sterol. The mass spectrum showed $\mathrm{M}^{+}$at $\mathrm{m} / \mathrm{z}$ at 412 corresponding to the molecular formula $\mathrm{C}_{29} \mathrm{H}_{48} \mathrm{O}$. The IR spectrum showed the presence of - $\mathrm{OH}$ group (3350 $\mathrm{cm}^{-1}$ ) and a peak at $1063 \mathrm{~cm}^{-1}$ corresponding to -CO- group. The ${ }^{1} \mathrm{H}$ - and ${ }^{13} \mathrm{C}-\mathrm{NMR}$ data of compound 2 were found to similar to that of $\mathbf{1}$ except two more olefinic proton signals in ${ }^{1} \mathrm{H}-\mathrm{NMR}$ at ä 5.02 (dd, $J=15.0,8.5 \mathrm{~Hz}$ ) and ä5.15 (dd, $J=15.0,8.5 \mathrm{~Hz}$ ) were assigned for olefinic protons at C-22 and C23 respectively. The coupling constant suggests that these protons are trans in position. From all these spectral analysis, the compound was identified as stigmasterol.

Compound 3 was obtained as white amorphous powder having melting point $284^{\circ} \mathrm{C}$. The mass spectrum showed the $\mathrm{M}^{+}$peak at $\mathrm{m} / \mathrm{z} 576$ corresponding to molecular formula $\mathrm{C}_{35} \mathrm{H}_{60} \mathrm{O}_{6}$. The IR spectrum showed the absorption of hydroxyl groups $3400 \mathrm{~cm}^{-1}$ and -C-O group at $1063 \mathrm{~cm}^{-1}$. The ${ }^{1} \mathrm{H}$ - and ${ }^{13} \mathrm{C}$-NMR data of compound 3 were found to similar to that of $\mathbf{1}$ except the signals of glycoside moiety resonate at ä 3.96-5.02. A signal at ä 5.02 was assigned for the anomeric proton of glucose moity attacked at C-3. Other multiplet at ä 4.27 was assigned for the proton of C-3. Its deshielding may be due to attachment of $\hat{a}$-O-glucosyl moiety at C-3 carbon. All the spectral values obtained from ${ }^{1} \mathrm{H}-\mathrm{NMR}$ and ${ }^{13} \mathrm{C}-\mathrm{NMR}$ and comparing with authentic compound the compound was identified as $\hat{a}$ - sitosterol glucoside (8).

Compound 4 was isolated as white crystalline solid, m. p. $75^{\circ} \mathrm{C}$. The EI-MS mass spectrum showed (m/z 424, $\mathrm{M}^{+}$) corresponding to molecular formula $\mathrm{C}_{29} \mathrm{H}_{60} \mathrm{O}$. IR spectrum gave hydroxyl group at $3350 \mathrm{~cm}^{-1}$ and C-O stretching at $1200 \mathrm{~cm}^{-1}$. The peak at 2992 $\mathrm{cm}^{-1}$ showed that the compound was aliphatic. The ${ }^{1} \mathrm{H}-\mathrm{NMR}$ spectrum showed a triplet equivalent to three protons at ä 0.88 $(J=7.0 \mathrm{~Hz})$ which were assigned as two terminal methyl group and a broad singlet equivalent to 34 protons at ä1.28 were assigned for 17 methylene groups in an aliphatic chain. The multiplet at ä 3.60 was assigned to the methane proton of the carbon containing hydroxyl group. All these evidences were in agreement with the compound being nonacosan-10-ol (8).

\section{CONCLUSION}

Tsuga dumosa D. Don is an economically as well as medicinally important Himalayan conifer. The Phytochemical screening and isolation of chemical constituents of T. dumosa afforded three sterols, namely $\hat{a}$-sitosterol (1), stigmasterol (2), â-sitosterol glucoside (3) and an alcohol, nonacosan-10ol (4). The structures of the isolated compounds were deduced from the analysis of spectroscopic data as well as with comparing with the authentic samples.

\section{ACKNOWLEDGEMENT}

The authors are highly thankful to Nepal Academy of Science and Technology (NAST) for providing laboratory facilities to complete this work and Prof. Dr. R. P. Chaudhary, Central Department of Botany, TU, for identification of plant.

\section{REFERENCES:}

1. Fang, J.M., Wu, S.K., Cheng, Y.S. 1985. Journal of the Chinese Chemical Society. 32(1): 75-80.

2. Fang, J.M., Wu, S.K., Cheng, Y.S. 1985. Journal of the Chinese Chemical Society. 32(4): 477- 480.

3. Bhattacharya, A., Valmore, C., Lamarche, Jr. and Malcolm, K.H. 1992. Tree-ring Chronologies from Nepal, Tree-ring Bulletin. 52: 59-66.

4. Zhao, Y.X., Luo, X.D., Zhou, J. 2005. Journal of Acta Botanica Yunnan, Yunnan Plant Studies. 2: 217-222.

5. Domb, A.J., Wolnerman, J.S. 2002. Eur. Pat. Appl. EP. 137: 12361244.

6. Zhao, Y., Luo, X., Zhou, J. 2004. Yunnan Zhiwu Yanjiu. 26(2): 229-233.

7. Zhao, Y., Li, C., Luo, X., Liu, Y., Zhou, J. 2005. Yunnan Zhiwu Yanjiu. 27(2): 217-222, 2005.

8. Gautam, L.N., Awale, S., Kalauni, S.K., Shrestha, K., Gewali, M.B. 2005. Scientific World. 3(3): 22-25. 